\title{
Geospatial Technology for Tourism Management in Aurangabad City
}

\author{
Pallavi U. Pandagale \\ Dept. of CS and IT, \\ Dr. B .A. M. University, Aurangabad (MH)-431005
}

\begin{abstract}
Aurangabad is a historic city located in the heart of Maharashtra. It is rapidly becoming a hot spot for tourist from around the world because of its exotic locations and facilities provide by the government. This paper describes the development of the tourism management and planning by the integration with the Geographic information system (GIS). This study covers tourism destinations which include tourist spots, historical spots, gate, museum, hotel, restaurants ,as well as complementing tourism destination services which include police station and hospital in Aurangabad city and how to the utilization of GIS technology can be used to improved tourism management. Also to model accessibility to these points of interest mentioned above using Geographic information system analytical tool and the function of the tourist industry is more and more emerging as the internet. Geographic coordinates of the location of all tourist spots, historical spots, gate, museum, hotel, restaurants, police station, hospital and various tourist destinations have been picked with their corresponding attributes to build a model using the Google earth/Google Map and KML file techniques. Analyses to aid a decision for management and future planning was carried out using the spatial statistical tools in the GIS application used for this study. A paper to present the tourist object in geospatial context on the interactive map supports planning the tourism and focusing on the analysis decision making and management using Google earth or Google map and KML file technique and finally presenting the result on the internet.
\end{abstract}

\section{Keywords}

Geographic information systems (GIS), Web based tourism application, Open Geospatial Consortium (OGC), KML.

\section{INTRODUCTION}

The world's largest and fastest growing sector of the global economy is in the tourism industry. It is defined as composite of facilities, activities, services and industries that deliver a travel experience that is accommodation, eating and drinking establishments, transportation, entertainment, historical and cultural experiences, destination attractions, recreation, shopping and other services available to travel away from home. The coastal lines on the touristic activities accelerated and the number of people participating that has been reached to more or more than 600 million a year. A maximum benefits or the zones coastal according to the basic of sustainable development possible using the management plans suitable the characteristics of the area and it is very common, becoming effective fast decision making using the possible GIS. Many companies are the software and support to the specific industry. The tourist industry using the GIS application are the analysis of current and potential client, analysis line of site for the new attraction such as bus routes, railway routes etc. In general when visitors are visiting tourism sites information about the location and of related services is important during and before such trips are made. When a visitor is on his way to a destination, he may want to know the shortest route to reach the destination of interest and also check for nearest facility within a specified distance or time to his or her current location. The GIS technologies are implemented in the tourism industry being that are future holds in the tip of the iceberg.

\section{CURRENT USE OF GIS TOURISM INDUSTRY}

The use of GIS system is therefore classified into two categories according to the client vis. Management user and public user. Public user is the tourists using the maps for navigating towards their destination. They are interested in tourism geographic or location specific information about a place or a region. Further, the tourist may be interested to know about the available amenities, facilities and also the climate of the region or place where they intend to visit. The management users consist of individual employers such as tour operators, tourism group, policy makers or a local municipal administration for tourism. Specific strategic planning or decision making. Management user is more interested to know the location of their socio-economic background and potential location for new tourist sites in the region.

\subsection{Study Area- Aurangabad city}

Aurangabad city is a historic city in located in the heart of Maharashtra. A tourist hub surrounded with many famous historical and culture monuments and natural resorts including the Ajanta and the Ellora Caves, Bibi ka maqbara and Panchakki and development of the tourism information with its modern tourist facilities, destinations, and activities. It is rapidly becoming a hot spot for tourist from around the world because of its exotic locations and facilities provide by the government. The city is located between $19^{\circ} 53^{\prime} 0^{\prime \prime} \mathrm{N}$ Latitude and $75^{\circ} 20^{\prime} 00^{\prime \prime} \mathrm{E}$ Longitude and the total geographical area of the is 135.75 sq.k.m .The city of 54 Gates but only 13 have survived over period of time and the presence of these can be felt as going on one drive in the city. In currently there are 35 tourist attractions/ locations in city and today city has annual inflow of 25 lakh tourists every year and which is still increasing. The Tourism potential of the district is not fully tapped due to international gaps, connectivity, Services Quality, inadequate basics amenities and marketing promotion. But there are various issues faced by the Aurangabad tourism for the development of tourism some of them are lack of proper infrastructure, Access and Connectivity, Amenities, Service level. The application providing information of places and enabling the provision of new smart services. Geographical Information allows users to view places as if standing upon them. Tour with a Themed 
Information, which highlights tourist attractions, provides its users a virtual tour of Aurangabad city. The help of the GIS application the tourist will be able to know the information about the place near city and explore about the tourist place all necessary information. Because of the development of the GIS based tourist information the visitors will be mange and plan their trips and complete their journey with more comfort and ease from the start to end and that can be determined easily and systematically using by the study area and exposed with the GIS but also proved that can be applied to these studies. The GIS can be acts as potential techniques in planning, managing and marketing the tourism products. Presently the tourism is being promoted and marketed to the world through the Internet and Web as one of the mediums of advertising. But still it is needs to be projected in a better way to the customer with the utmost possible information to increase its marketability. Geospatial data can be used to enhance the tourist web site of a region which will give a new look with added functions to browse the information in a more innovate, interesting and better way, so that the prospective tourist researcher turns into a tourist for the region.

\section{DATA COLLECTION}

The technologies within the language of open geospatial consortium (OGC) standards in-order to more fully understand urban systems.[1] Working with the KML and Google API for locating the available \& analyzing their properties for tourist information system in the Aurangabad city. Designing and developing a website that provides both spatial and non-spatial tourism information using Google earth/Google map KML language. In the first step collect all tourist sport, historical sport, historical and cultural socioeconomic data, facilities concerning to the study are form a database. Second data that are regarding to the study area and these data related with the database formed in the tourism information system that provide details about these tourist locations like their address and operating time and various other details. Those support public access of data to get calculative information while giving efficient way to organization to represent them. Third obtain of the historical and cultural in the city tourist place and hotel to connect with the graphical data in the tourism information system. Fourth they prepare a software an which is developed to the tourist query and tourist which is uses tourism information system the fastest and easiest by icons and sign. Fifth this step of the study is use required software to transform tourism information system. Which it is a formed with all visual, literary, and graphical data into a system can be supply a query on internet. This is challenging objective, all the complex information generated is to be managed geographically. Managing geographically and representing organization, places give user an efficient way to get structure easily.

\section{LITERATURE SURVEY}

The advancement in modern technology many opportunities for the application of Geographic information system (GIS) in tourism are available for the development of the tourism sector. The fusion of remote sensing with the Geographical Information System (GIS) technologies has been vastly implemented and recognized effectively in the urban analysis and modeling. According application of SPOT data for regional growth analysis and local planning and GIS is recognized widely and accepted as a valuable tool for analyzing, managing, and displaying large volumes of diverse data pertinent to many local and regional planning activities. Its use in tourism planning and management becomes imperative. (Ethlers, M.; Jadkowski, M.A.; Howard, R.R.; Brostuen 1990, 56,175-180).[2]. A study on the value and scope of geographical information system in tourism management the main objective were to overcome the shortterm management strategies or an ignorance of more sustainable form of tourism. Most importantly it is necessary to clearly understand the nature, scope and impact of the TDA when evaluating the relevance and benefits of a GIS. [3]. The recent technology developments based on Geographic Information System (GIS) and satellite images have provided a new way of accessing location-based information. It can provide with the interactive mapping services as well as realistic satellite images and more importantly the free application programming interface (API) allows thousands of programmers to tap into the powerful Google mapping service by connecting it with various types of data Combined with destination-specific tourist information. It could provide a new way of trip planning and tourist information accessing. [4].This study on the Tourist Information System for tourism development in the Pune district. The main objective was to collect the information about tourism facilities available at that time and to find out the potential tourist sites and their suitability in the area with the help of GIS technique. [5]. The research on the geographical investigation of tourism in Raigad district. It was observed that the conditions of state highway, district roads and village roads were not at all satisfactory which was one of the main drawback in the development of the region as a tourist centre, as it was a mandatory to develop the various government authorities such as PWD, MTDC and local leaders were intimated and were said to take the matter into consideration and take lead and were to develop the roads and routes for the transportation were to be improved. [6]Rajasthan Development Tourism consisting of various statistical tools such as standard, mean deviation, coefficient of variance and $t$ test were employed. A detailed view on the data was made, classified and analyzed using all type of relevant techniques implement the most appropriate tests. As per the government, all the private entrepreneurs should contribute to this sector, due to which it will help to increase and raise the revenue, to develop and serve the tourists with the best services and for the further enhancement of the tourism sector. [7].The developing on the thematic maps online with the help of php, $\mathrm{kml}$ and Google earth API for visualizing the indicators selected for the Slovak republic. The key was to evaluate the existing Web applications was to the demonstrate and a general possibilities of using PHP scripting language and KML format in the field of Thematic Mapping. And the advantage of this format is its direct support for multiple application and services generated by Google and therefore the possibility to combine features and functionality of multiple products into one compact unit. The benefit of applying methods of the thematic mapping it is also a clear visual interpretation of these maps by the general public. It's a chance to become familiar with the results of the geographic research in very interesting and attractive userfriendly form. [8]. A case study on the GIS in tourism management in China it was found that the roles of GIS in tourism management are mainly in the areas conducting tourism information management and enable to produce a comprehensive thematic map. The existing problems of GIS applications in tourism management at take a panoramic view of the current technology and management system, the key technology and problems to the development and implementation of the GIS were the construction of tourism geographic information database, the data structure and the data model in the design of Tourism Geographic Information Database System [9]. The social impact of Ellora caves on the 
geographical influence of Aurangabad city. The main objective of the research was to highlight the social development in the study region and promote the social importance of tourism in human life. It was also suggested that MTDC should take steps that would attract foreign tourists towards this place. [10]. The Maharashtra Tourism Development Corporation (MTDC) started a project as VISION TOURISM 2020in 2010 for the development of tourism sector in Aurangabad. According to the draft plan the main aim of the project is to produce a world class Visitor experience for the Tourists to Aurangabad district leading to their prolonged stay thus developing the ensure the safety, security and comfort, local economy and community of the visitor without degrading the environmental, cultural and social values at the world populace. [11]

\section{IMPLEMENTATION}

The categories of the information users are people within the public that will be need to access the database that will be designed and implemented. This study the following users have been identified and their needs are the primary data were acquired through field survey using Google API to acquire point data in terms of coordinates of points where tourist /historical place, gate, Museum hotels, Restaurant, Museums, Hospitals, clinics, police stations are located in Aurangabad city. The data captured where grouped into different categories which included Facilities, Services, and tourist's destinations. Each facility, services, and tourist's destination were given to different unique identifiers .This project used for the secondary data was an existing road map of Aurangabad city. It was converted to digital form and Geo referenced using coordinate of known points. The software used executes and drive the database is Google earth/ Google map, API, KML file in Geo database.

\section{A. Database Design}

- The tourists and residents or public.

- The government agency in charge of tourism.

- Emergency service providers.

- Law enforcement agencies.

The user's requirement is here guided on the type of information needed to build the database.

\section{B. Conceptual Design}

It is involves defining the entities which are the view of a reality relevant to the study as shown in Table 1 .

- The road networks are represented as line features.

- The Tourists Destinations in Aurangabad city which included tourist/ historical place, Gate Museums, are represented as points.

- The Tourists Facilities in Aurangabad city which included hotels, restaurants, are represented as points.

- The Services Aurangabad city which includes hospitals and police station are represented as points.

\section{Logical Design}

It involves the transmitting or translation of the conceptual schema into logical schema. It is also involves selecting the implementation software. Here within the entities identified become relations with attributes.
Table 1- Facilities Entity and its Attributes

\begin{tabular}{|l|c|}
\hline \multicolumn{1}{|c|}{ Field } & Description \\
\hline F_Id & Facility identifier \\
\hline F_Name & Facility name \\
\hline F_Type & Facility type \\
\hline F_Street & Facility street location \\
\hline F_Address & Facility address \\
\hline F_Product & Facility product \\
\hline
\end{tabular}

\section{Database Creation}

The point coordinates of tourist /historical place, gate, museum, hotels, restaurants, hospitals, police station were collected using Google API, the data sorted respectively. The point coordinates is grouped as tourism destinations, facilities and services, and a feature class each and their corresponding attribute fields is created in the Google earth/ Google map Geo database using the Google earth to store the point data and their corresponding attributes. The point data into Google earth software application in Geo database and the edit mode is turned on the feature class attribute table is opened. The point each is selected using the select tool and its corresponding attribute is added into the database. The tourist /historical place, gate, museum, hotels, restaurant, police station were grouped as facilities because they complement tourists destinations and given different unique identifiers in the facilities feature class. The process is also applied to the services feature class and the tourists destination feature class. For the purpose of analysis, the facility feature class is broken down into separate feature class in the Geo database. The analysis purpose they were also separated into different layers but still retained the properties of the service feature class in the Geo database. The reason for doing this is to use thematic layers to run analysis instead of using a whole group called facilities and the group theme of facilities will be function effectively in database queries.

\section{E. Network Analysis}

This study network analysis is carried out to determine the path from points on the network to tourist's destinations, facilities and services. The network analysis tool is a vital component of Google earth /Google map .Google API, KML file software employed in this project. It is used in analyzing transportation line to determine shortest and fastest path within a network. A simulation of path was carried out on how tourists can move from hotels to tourist's destinations and restaurants in Aurangabad city. The analysis here is to simulate the optimal path tourist will take when moving within a network and criteria's used in building this network included additional attribute fields such as "road length in meters, Speed limit and drive time". The drive time calculated by dividing the road length in meters by the speed limit and by 60 which represent minutes and this attributes were incorporated to the network that was built for this study as shown in eq. (1).

Drive Time $=$ length in meters $/$ speed limits $* 60$

In simulating a path for tourists place possible in which tourist may want to visit were added has network location. For example i.e. evident those tourists will want to move from their hotel rooms to restaurants or to the tourist destination and also visit various point of interest within Aurangabad city. For easy data loading to the various points on the network where tourist destinations exist ,facilities exists, and services existed, those points were using address in the geo database using Street referencing system. 


\section{RESULTS}

In the Fig. 1 below a stop at Bibi ka Maqbara is selected and added has a network location, this stop is the location of "Railway station" on the network. Using the address locator another location is added to the network depicting a hotel facility named "Orientals", where tourists can decide to go within the network. The two other locations within the network are also added using the address locator making the number of stops within the network to be four. The first stop is a "tourist place" at Panchakki, the second stop is a "Ghati", the third stop is a "Barapulla gate" at and the last location is a "Bus stand". The result displayed will show the directions, distance and time it will take tourists to move around points of interest within the network. For the purpose of this analysis, the setting used is as follows are impedance used were minutes attributes, direction distance units were kilometers.

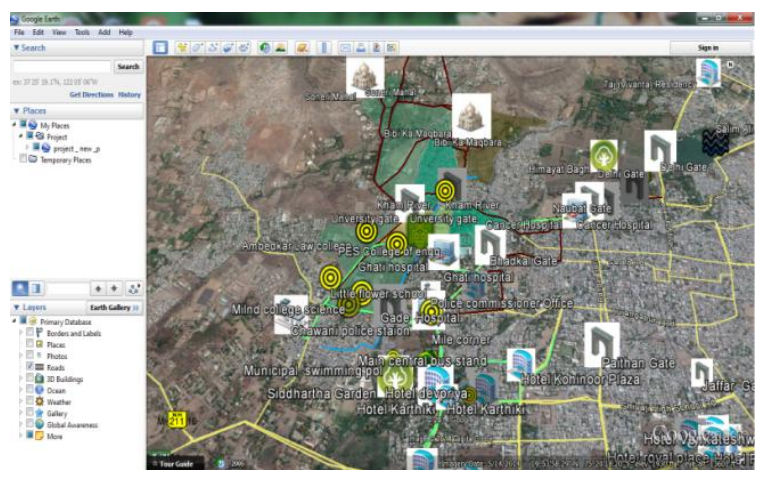

Fig 1:- Result Alternative Path Analysis BibiKaMaqbarato Railway Station

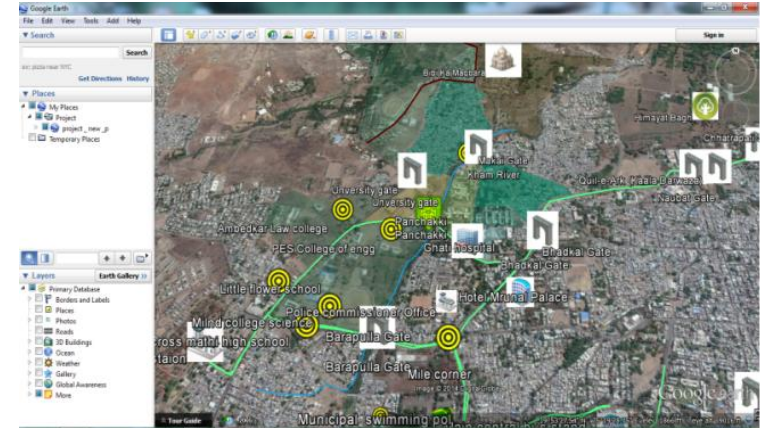

Fig.2: Path Analysis Bibi Ka Maqbara to Railway Station

Fig. 2 shows that to move along all the four locations selected on this network which is between Bibi ka Maqbara to railway station and, it will take tourists 6.724439 minutes which has been approximated to 7 minutes to cover a distance of 7.5 kilometers while driving assuming no traffic on the road. The same route is selected to simulate and compare the route when there is a barrier at different point on the network. The analysis performed using Google earth and KML techniques the network analyst is the service area analysis. This coverage area determine used a particular service or facility within the study area can serve by specifying parameters which can be in terms of time or meters attribute created as impedance while the network was built. For the purpose analysis the impedance unit used is the minute attributes and the impedance minute specified is 5 minutes. For the direction away from the facility is selected and the accumulation attributes used are meters and minutes. The location of the service facility was added using the address. For ex the

Service used in a hospital named Ghati and it is located at Panchakki road in the Aurangabad city.

Table 2: Result of Path Analysis

\begin{tabular}{|c|c|c|c|c|}
\hline Routes & Distance & Drive Time & $\begin{array}{c}\text { Difference in } \\
\text { Distance }\end{array}$ & $\begin{array}{c}\text { Difference in Drive } \\
\text { Time }\end{array}$ \\
\hline $\begin{array}{c}\text { BibiKaMaqbara to Railway } \\
\text { Station (Best Path) }\end{array}$ & $7.5 \mathrm{Km}$ & $7 \mathrm{~min}$ & $3 \mathrm{Km}$ & 3 min \\
\hline $\begin{array}{c}\text { BibiKaMaqbara to Railway } \\
\text { Station } \\
\text { (Alternative Path) }\end{array}$ & $10.5 \mathrm{Km}$ & $10 \mathrm{~min}$ & $3 \mathrm{Km}$ & Same drive time \\
\hline $\begin{array}{c}\text { BibiKaMaqbara to Bus Stand } \\
\text { (Best Path) }\end{array}$ & $5.8 \mathrm{Km}$ & $7 \mathrm{~min}$ & $2.5 \mathrm{Km}$ & 1 min drive time \\
\hline $\begin{array}{c}\text { BibiKaMaqbara to Bus Stand } \\
\text { (Alternative Path) }\end{array}$ & $8.3 \mathrm{Km}$ & $7 \mathrm{~min}$ & $2.5 \mathrm{Km}$ & 1 min \\
\hline $\begin{array}{c}\text { Panchakkito Bus Stand (Best } \\
\text { Path) }\end{array}$ & $4.1 \mathrm{Km}$ & $3 \mathrm{~min}$ & $3.4 \mathrm{Km}$ & $\mathrm{Km}$ \\
\hline $\begin{array}{c}\text { Panchakkito Bus Stand } \\
\text { (Alternative) }\end{array}$ & $7.5 \mathrm{Km}$ & $4 \mathrm{~min}$ & & \\
\hline
\end{tabular}

The hospital location is used to analyses converge area it can serve within the network should in case of emergencies arising within facilities and tourist destinations within the network. Table 2 shows that the result of hospital can serve various the facilities such as hotel, restaurant and tourist / historical spots within the network at an impedance of 5 minutes and 5 minutes' drive time specified except for area. 


\section{CONCLUSIONS}

This study covers tourism destinations which include tourist spots, historical spots, gate, museum, hotel, restaurants ,as well as complementing tourism destination services which include police station and hospital in Aurangabad city and how to the utilization of GIS technology can be used to improved tourism management. The model also to accessibility to these points of the interest mentioned above using Geographic information system analytical tool and the function of the tourist industry is more and more emerging as the internet. Geographic coordinates of the location of all tourist spots, historical spots, gate, museum, hotel, restaurants, police station, hospital and various tourist destinations have been picked with their corresponding attributes to build a model using the Google earth/Google Map and KML file techniques. Analyses to aid a decision for management and future planning were carried out using the spatial statistical tools in the software application used for the execution of this project. The result was overlaid on the path layer to identify the street location central. This research has able to demonstrate the dynamic capabilities of Geographic information system application in mapping, analysis and modeling of Geographic phenomenon. This tool will aid tourism planning authorities, tourists Government Agencies to visualize a plan, and access to various tourists Destinations, Facilities and Services in Aurangabad city The tourism resources and facilities it has to offer and also will aid resident's social night life and will be increase the tourist ability to make choice using the network analyst function of Google earth and KML file application software which helps in ascertaining shortest route, nearest facilities from their current location.

\section{ACKNOWLEDGMENTS}

The author would like to thank the University Authorities for providing the infrastructure to carry out the research. This work is supported by University Grants Commission .Author would also wish to express deep sense of gratitude and indebtedness to our guide, for the meticulous guidance, valuable discussion and idealistic suggestions during study. He has supported, helped and encouraged me in all ways.

\section{REFERENCES}

[1] OGC® Approves KML as Open Standard Sam Bacharach Executive Director, "Outreach and Community Adoption Open Geospatial Consortium".

[2] Ethlers, M.; Jadkowski, M.A.; Howard, R.R.; Brostuen" SPOT data for regional growth analysis and local planning and GIS “, 56,175-180, 1990.

[3] David McAdam, "The Value and Scope of Geographical Information Systems in Tourism Management", International Journal of Science, Research (IJSETR), 1999.

[4] Duran, Seker, \&Shrestha, "Trip planning and tourist information accessing", 2004.

[5] Dr. Virendra R. Nagarale, "Tourist Information System and Their Site Suitability with the Help of GIS Techniques", 2007

[6] Prakash J Hajare, "The research on the geographical investigation of tourism in Raigad district”, July 2012.

[7] Laveena T. Dharmani, "Rajasthan Development Tourism", 2005-2010

[8] Vladimir Bacik "Creating thematic maps online using PHP, KML and Google Earth, an example of visualizing selected indicators for the Slovak republic".

[9] Wei Wei," A case study on the GIS in tourism management in China", 2011

[10] Dr. Madanlal V suryavanshi, "The Social Impact of Ellora Tourism as a Geographical Study", International Research paper, volume3, Issue4, April 2013.

[11] The Maharashtra Tourism Development Corporation (MTDC) started a project as VISION TOURISM 2020in 2010 for the development of tourism sector in Aurangabad. 